\title{
Occupational Health Hazards in Current Dental Profession- A Review
}

\author{
Ramandeep Singh Gambhir ${ }^{*}, 1$, Gurminder Singh ${ }^{2}$, Sumit Sharma ${ }^{3}$, Rajdeep Brar ${ }^{4}$ and Heena Kakar ${ }^{5}$ \\ ${ }^{I}$ Dept. of Public Health Dentistry, Gian Sagar Dental College and Hospital, Rajpura, Punjab, India \\ ${ }^{2}$ Dept. of Prosthodontics, Gian Sagar Dental College and Hospital, Rajpura, Punjab, India \\ ${ }^{3}$ Dept. of Periodontics, Gian Sagar Dental College and Hospital, Rajpura, Punjab, India \\ ${ }^{4}$ Dept. of Oral Medicine and Radiology, Punjab University Dental College, Chandigarh, India \\ ${ }^{5}$ Apollo Dental Centre, Chandigarh, India
}

\begin{abstract}
Dentists, as well as other dental personnel are constantly exposed to a number of specific occupational hazards. These cause the appearance of various ailments, specific to the profession, which develop and intensify with years. In many cases they result in diseases and disease complexes, some of which are regarded as occupational illnesses. Relying on relevant literature, the present paper discusses occupational hazards like stressful situations, latex hypersensitivity, allergic reactions due to various dental materials, exposure to radiation (ionizing and non-ionizing), percutaneous exposure incidents (PEI), hazard due to nitrous oxide gas, as well as factors leading to the musculoskeletal system diseases and diseases of the peripheral nervous system. Awareness regarding these occupational hazards and implementation of preventive strategies can provide a safe working environment for all the dental personnel. There is also a need for continuing dental education programs in dentistry so that dentists can update themselves with the latest and newer techniques and materials.
\end{abstract}

Keywords: Dental personnel, hazards, stress, allergy, infection.

\section{INTRODUCTION}

Occupational hazard can be defined as the risk to the health of a person usually arising out of employment. It can also refer to work, material, substance, process or situation that predisposes or itself causes accidents or disease at work place. The history of occupational hazard awareness can be traced back to the $18^{\text {th }}$ century when Bernadino Ramazzini, who is referred to as the 'Father of Occupational Medicine', recognized the role of occupation in the dynamics of health and diseases [1].

Occupational health hazards are not uncommon $[2,3]$. Although modern dentistry has been cited as the least hazardous of the all the occupations [4], many risks still challenge the status of this occupation. Studies have shown that dentists report more frequent and worse health problems than other highrisk medical professionals [5]. Dental personnel are exposed to various occupational hazards like stress, allergic reactions, higher noise levels, percutaneous exposure incidents, radiation, musculoskeletal disorders, legal hazards etc. This is in accordance to other studies where occupational hazards such as interactions with patients, physical strain and financial pressure negatively related to psychological wellbeing of dental professionals [6-10]. A part from this, dental environment is also associated with a significant risk of exposure to various micro-organisms. Infectious agents may be present in blood or saliva, as a consequence of bacterimia or viremia associated with systemic infections. Dental patients

*Address correspondence to this author at the Gian Sagar Dental College, Rajpura, Punjab, India. PIN- 140601, India, Tel: +91-99156-46007; Fax: +91-1762 520011; E-mail-raman1g@yahoo.co.in and Dental Health Care Workers [DHCW] may be exposed to variety of micro-organisms via blood or oral or respiratory secretions [1]. These micro-organisms may include cytomegalovirus, hepatitis B virus, hepatitis C virus, herpes simplex virus types 1 and 2, HIV, mycobacterium tuberculosis and other viruses and bacteria, especially those that infect the upper respiratory tract [11]. Microorganisms can pass into organism, through a cut on the skin of his/her hand while performing a medical procedure, any dental procedure resulting in an accidental biting by the patient, or through a needle wound created while imparting anaesthesia. An indirect infection occurs when an infectious agent is transmitted into organism through the so-called carrier. The following are the main sources of indirect infection: aerosols of saliva, gingival fluid, natural organic dust particles (dental caries tissue) mixed with air and water, and breaking free from dental instruments and devices [11]. The current paper reviews various studies relating to occupational health hazards in dental profession hoping to update previous studies [12].

\section{METHODS}

An extensive review of literature was done which engaged most of the articles published in peer-reviewed journals relating to the subject of occupational health hazards in dentistry. The review itself began with the search of relevant key words linked with the dental and medical profession like occupational health, occupational disease, dental hazards etc. in various search engines including pubmed. Reports published only in English language were included in the review. The spot light of the present review would not only be on the occupational health hazards in dentists but studies on other dental staff are also included. The search also targeted dis- 
eases like stress, musculoskeletal disorders, allergic reactions, higher noise levels. The present review noted that a part from these hazards there are also other occupational hazards which were not seen in the past like legal hazards and suicidal tendencies in dentists.

\section{Global Prevalence of Occupational Health Hazards}

A wide variety of work place risks are known to exist in dental profession at a global level (Table 1). A previous study reported that public health dentists reported occupational health related problems such as dermatoses (40\%), eye, respiratory and systemic complaints (13\%) [13]. In India, an investigation among Navy dentists revealed that $47 \%$ of them experienced an injury from a sharp instrument during the past six months and backache was the commonest hazard in $70.6 \%$ of the personnel followed by occasional anxiety and wrist ache [14]. Latex allergy and glove dermatitis were reported in $9 \%$ and $22 \%$ of dental personnel respectively in a dental school in Australia [15]. Another study carried out among the dental students studying at University of Cartagena reported that $80 \%$ of the students suffered from muscular pain due to the clinical practice; the clinical areas where more pain was found were surgery and periodontics and $15 \%$ of the students reported pain in the neck and lumbar zone [16]. In a study conducted among dentists and dental auxiliaries in Riyadh, Saudi Arabia about the prevalence of hearing problems in the last five years, $16.6 \%$ of subjects reported to be suffering from tinnitus, $30 \%$ of the subjects had difficulty in speech discrimination and $30.8 \%$ of the subjects had speech discrimination in a background noise [17]. Chronic back pain, headache and musculoskeletal symptoms were experienced by $55.1 \%, 88.7 \%$ and $86.5 \%$ of dental practitioners respectively in a large investigation conducted in Lithuaniana [18]. A study conducted among dentists in Southern Iran reported that $33 \%$ of them were suffer-

Table 1. Categorization of Potential Hazards Encountered in Dentistry

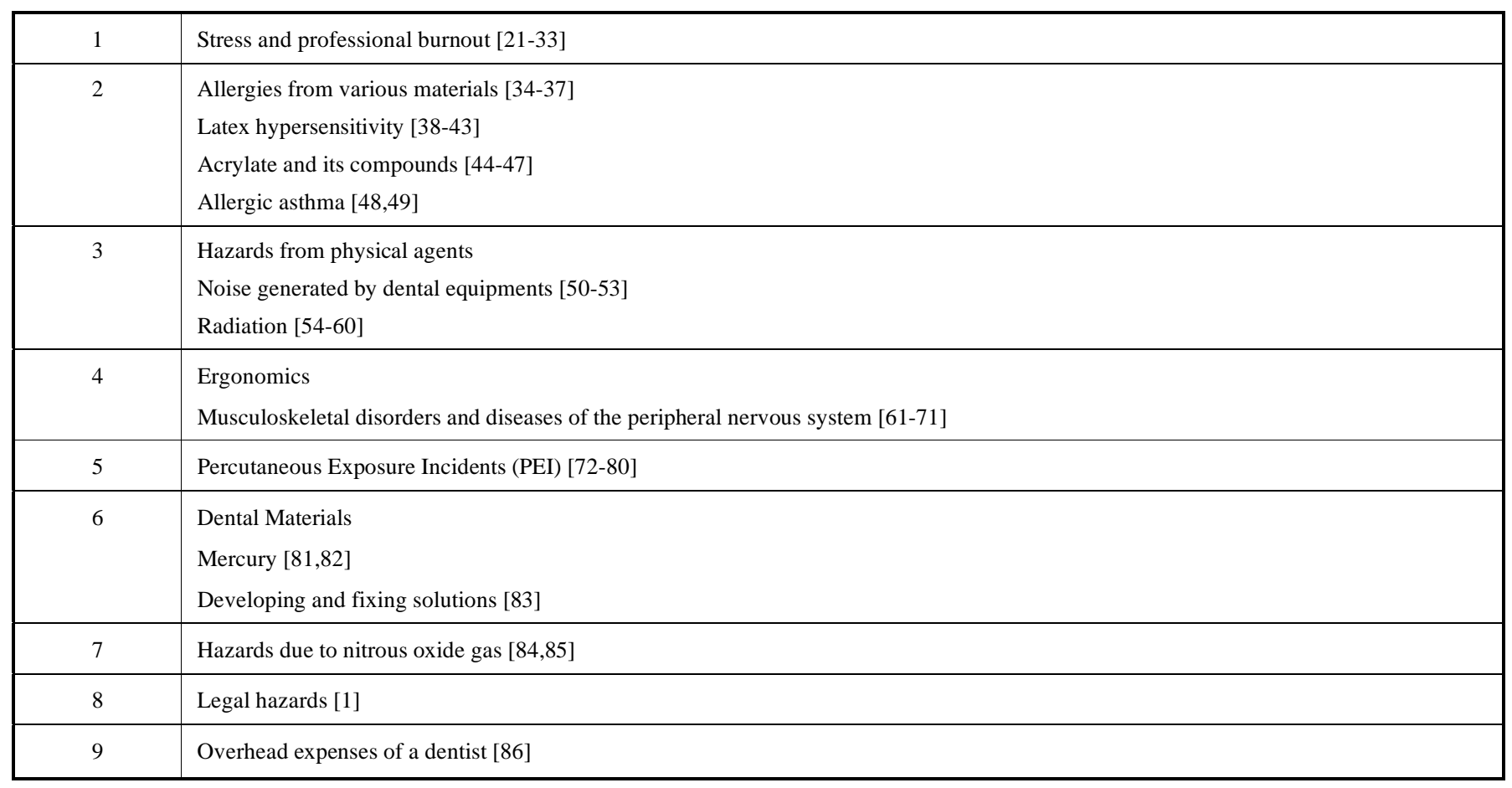

ing from lower back pain while $28 \%$ had neck pain [19]. Another survey conducted in Lithuaniana dentists reported that majority $(95.1 \%)$ of them revealed that dental profession influences their general health and more than a half $(52.4 \%)$ experienced health complains on either a frequent or very frequent basis [20].

\section{Stress}

Stress situations form an intrinsic part of a dentist's occupation. Although seldom discussed, they should be considered in view of the hazards connected with this profession.

Although dentists are generally regarded as healthy and miss very few of the working days during their working life as compared to others [21,22], illness and time off for illnesses have been found to increase with age [22].

\section{Sources of Stress}

Many clinical situations produce stress to a dentist [2327] and these include, among others, procedures connected with anaesthetization of patients, overcoming of pain and fear, unanticipated emergency situations in which a patient's life is in danger, or procedures with hesitant prognosis. According to a study [27], administration of anaesthesia to patient is seldom discussed and it forms a major source of stress in this profession. Unskillful planning of a treatment may be source of disappointment and pain associated with failure both to a doctor and a patient. In many dentists an inseparable presence of stress situations may elicit painful thoughts, emotions or fears. It may also contribute to the development of such instantaneous reactions as increased tension, high blood pressure, fatigue, sleeplessness, touchiness and depression [28].

The psychological aspects of dentist-patient co-operation are very important. In everyday clinical practice a dentist has 
to adapt an individual attitude towards a patient, depending on his/her mental state \& personality. A stress situation is produced if the patient is not satisfied with the treatment rendered by the dentist. In most cases, the knowledge of psychology, good communication skills and establishment of a proper relation between dentist and the patient are the most crucial factors which decide the outcome of the treatment. Good communication between the doctor and the patient has a positive influence upon a stricter observance of the doctor's recommendations by the patient. The course of doctorpatient relations significantly reflects patient's health action and result of treatment $[29,30]$.

Concerning substance abuse, the most commonly reported cause of impairment amongst dentists is chemical dependence [31]. Most modern dentists report use of alcohol or other drugs, although according to a previous study more male dentists consumed alcohol as compared to female counterparts [29]. Rates of alcohol consumption vary greatly between dentists in different parts of the world [4, 32]. Rate of smoking among dentists is still high in different countries [33].

\section{Allergic Reactions}

An occupational allergic reaction particularly of the hands is a common problem among dental personnel [34]. Two main types of dermatitis are contact dermatitis and atopic dermatitis. A study from Thailand reported one-fifths of dentists suffering from contact dermatitis [32]. Approximately one-third of dentists and dental hygienists reported hand dermatoses in few other studies [35-37].

\section{Latex Hypersensitivity}

An intrinsic part of dentist's protective equipment includes gloves and mask. Latex gloves have been worn routinely in dental profession for more than two decades and are basis of good infection control strategies. However, the residual or intergral chemical components pose a potential health hazard to some dental staff and patients [38]. Latex gloves dusted with corn-starch powder are most often used. The gloves and mask form an inbuilt barrier against most pathogens, and as recently proven, they also constitute a very good barrier against viruses, provided that the gloves and mask are intact [39]. However, they may produce allergic reactions primarily in those persons who use rubber products on regular basis and dentists fall in this category.

The most important risk factor of immediate allergies is frequent exposure to latex products [40-42]. Sensitization may occur through inhalation of air borne powder or through the skin. Inhaled glove powder is capable of inducing type 1 hypersensitivity responses but the most common type of allergic reaction is the delayed hypersensitivity or allergic contact dermatitis [38]. Atopy is another essential factor contributing to the increased number of allergic cases. A study reported that atopy was 2.2-4.5 times more frequent in those health service employees who were allergic to latex than in those who were not allergic. It is estimated that $2.8-17 \%$ of the employees of health service are allergic to latex. $8.8 \%$ of dentists were found to be allergic [42].

The clinical symptoms of latex allergies include: urticaria, conjunctivitis accompanied by lacrimation and swelling of eyelids, mucous rhinitis, bronchial asthma and ana- phylactic shock. Corn-starch or the so called absorbable dusting powder also plays an important role in latex allergies, manifesting itself in the reaction on the part of airways. This powder is not biologically neutral, as was previously thought. It is allergenic and takes part in immediate allergic reactions [43].

\section{Acrylate and its Compounds}

Dental polymer materials based on methacrylate, its polymer, and polyelectrolytes, seem to be a major cause of contact dermatitis in dental personnel [44-46]. Dentistry uses variety of different polymer materials. The setting of restorative materials and adhesives is initiated chemically by mixing two components or by visible light. In both cases, polymerization is incomplete and monomers not reacted are released [47]. These free monomers may cause a wide range of adverse health effects such as irritation to skin, eyes or mucous membranes, allergic dermatitis, asthma and parasesthesia in the fingers. Additionally, disturbances of the central nervous system such as headache, pain in the extremities, nausea, loss of appetite, fatigue, sleep disturbances, irratibility, loss of memory, and changes in blood parameters may also be noted.

\section{Asthma Due to Acrylate Compounds}

Allergic respiratory problem due to dental materials is also an important occupational hazard. A previous study reported occupational asthma, conjuctival symptoms and allergic contact dermatitis among dental technicians exposed to acrylate compounds [48]. Another study was conducted on occupational asthma among dental technicians by determining time-weighted average and peak concentrations of methacrylate vapor and time -weighted average concentration of acrylic dust [49]. It suggested that the use of a local exhaust ventilation system significantly reduced the peak concentration of methyl methacrylate vapor in the breathing zone of dental technicians. However, the local exhaust ventilation was not efficient in reducing the concentration of airborne acrylic dusts.

\section{Hazards from Physical Agents \\ Noise Generated by Dental Equipments}

Dental personnel are exposed to noise of different sound levels while working in dental clinics or laboratories. Dental laboratory machine, dental handpiece, ultrasonic scalers, amalgamators, high speed evacuation devices and other items produce sound at different levels which is appreciable. As reported in an earlier study conducted among dentists and dental auxiliaries, $16.6 \%$ of subjects reported of tinnitus, $30 \%$ had difficult in speech discrimination and $30.8 \%$ had speech discrimination in a background noise [16]. The noise levels of modern dental equipment is below $85 \mathrm{db}$ and up to this point the risk of hearing loss is negligible [50,51]. But the risk is amplified while using older or faulty equipment.

In dental practical classes, the acoustic environment is characterized by higher noise levels, in relation to other teaching areas, due to exaggerated noise produced by some of these devices and to the use of dental equipment by many users at the same time. This situation is aggravated when the classrooms have hard surfaces which act as noise reflectors, as is usually the case [52]. Therefore, it should be guaranteed 
that, in school buildings of this type sound levels are not detrimental to learning activities. Harmful effect is produced on the students and lecturers due to long exposure to higher noise levels. It is well known that higher sound levels have a negative effect on the extra-auditory systems with physical consequences (quickened pulse, increase in blood pressure, constriction of blood vessels, etc.) and psychical consequences (nervousness, mental fatigue and emotional frustration, low productivity etc) in some individuals. These effects occur especially with noise levels above $80 \mathrm{db}$ and are dependent on the intensity, the distance to the source, the total duration of the noise, the age of the individual and his/her physical condition and sensitivity [50, 51]. Also, it is commonly known that exposure to noise can induce loss of hearing. It is therefore essential to control noise in learning environments, not forgetting that acoustic comfort depends not only on the control of the emitted sound levels but also on the acoustic characteristics of the classrooms.

Ultrasonic scalers sometimes may be a potential hazard to the auditory system of both clinicians and patients. Damage to operator hearing is possible through air-borne subharmonics of the ultrasonic scaler. For the patient, damage can occur through the transmission of ultrasound through the tooth contact to the inner ear via the bones of the skull. This later hazard is possible during the scaling of molar teeth [53]. Tinnitus is an early sign of hearing loss and may occur following ultrasonic scaling in some individuals. A small number of dentists have experienced tinnitus or numbness of the ear after the prolonged use of ultrasonic scaler, which indicates a small potential risk to hearing.

\section{Radiation}

Dental personnel are exposed to both ionizing and nonionizing type of radiations. Ionizing radiation is a wellestablished risk factor for cancer [54]. However, despite the fact that most dental offices and clinics have $x$-ray machines that are in frequent use [55], the exposure of dental workers to ionizing radiation and the associated potential cancer risk have been assessed in only a few studies. Dental staff should stand behind protective barriers and also use radiation monitoring badges to protect themselves. Non-ionizing radiation has become an important concern with the use of blue light and ultra-violet light to cure various dental materials. Exposure to the radiations emitted by these can cause damage to the various structures of the eye including the retina and the cornea [56]. Use of safety glasses and appropriate shields can minimize or eliminate the radiations in this regard.

A study conducted among Canadian dentists reported that occupational doses of ionizing radiation among dentists and dental workers have decreased markedly since the 1950s [57]. The incidence of cancer among dental workers was lower than that for the Canadian population for all cancers except melanoma of the skin. Direct radiation injury has been virtually eliminated by improvements in radiologic equipment and methods and radioprotection measures [58]. However, the potential effects of whole-body doses remain of concern [59], with secondary radiation scattered from bones in the patient's head now representing the greatest source of radiation received by dentists and dental workers [60].

\section{Ergonomics}

\section{Musculoskeletal Disorders [MSD] and Diseases of the Peripheral Nervous System}

Muscular pain is a common affliction in dentists which begins at the time they start their professional studies and it stays with them during their professional practice affecting the spine, neck, shoulders and hands, among others [61]. It has been proven that postures which may exert a higher pressure on intervertebral disk as well as prolonged spinal hypomobility are among important factors leading to degenerative changes in the lumbar spine and subsequent lower back pain. Musculoskeletal pain, particularly back pain has been found to be a major occupational health hazard in dental profession [62-64]. A Finnish study reports musculoskeletal symptoms from the back and neck of $30 \%$ of the dentists. In an American study, $57 \%$ of 960 dentists in a Dental Society reported occasional back pain [65].

At work, the dentist works in a strained posture (both while standing and sitting close to a patient), which eventually leads to overstress of the spine and limbs. This refers to the $37.7 \%$ of the work time. The overstress produces a negative effect on the musculoskeletal system and the peripheral nervous system; above all, it affects the peripheral nerves of the upper limbs and the neck nerve roots [66, 67].

Spine degeneration leads to back pain syndromes which are reported frequently in dental personnel. Neck discopathy results in cervical pains or cervico-acromial pains, which are particularly common among dental practitioners [68]. The posture which the dentist assumes at work with the neck bent and twisted, an arm abducted, repetitive and precise movements of the hand, are a frequent cause of the neck syndrome and of pain within the shoulder and upper extremities [69].

Lumbar and lumbosacral discopathy arouses pain in the loins and the lower back radiating to the lower extremities, more often right than left. This can be explained by a greater stress on the right side of the body when the doctor works with a sitting patient. The dentist makes constant monotonous movements, which stress the wrist and elbow joints. Also of consequence are mechanical vibrations which are produced by some dental equipment like ultrasonic scalers and handpieces and are transmitted to hands and arms. In addition, the extensive use of handtools in dentistry work can cause a chronic extrinsic compression of the nerves in the hand, and therefore may cause an entrapment of digital nerves [70]. Whatever the cause of the symptoms, neurological disturbances are potentially serious in an occupation in which precise hand movements are necessary.

Median nerve and cubital nerve defects are seen in a number of dental doctors. An early syndrome of a defected median nerve shows in acroparasthesiea. A consequence of the defected median nerve in the carpal nerve is the so-called tunnel syndrome. Its early phase is dominated by paroxysmal parasthesiae of the thumb and the index finger, which occurs almost without exception at night and which is accompanied by sensomotor disorders of the thumb and the index finger [71].

Operations carried out during extractions stress not only the elbow joint and the wrist joint but may result in chronic tendon sheath inflammation. The long-term effect of all 
those adverse circumstances occurring in the work of the dental doctor may lead to diseases described as cumulative trauma disorders [71].

\section{Percutaneous Exposure Incidents [PEI]}

Percutaneous injuries are a frequent problem among dentists, who are among the healthcare professionals most involved in occupational accidents [72] particularly needlestick and sharp instrument injuries [73,74]. This exposure is related to the fact that dentists work in a limited-access and restricted-visibility field and frequently use sharp devices. Percutaneous exposure incidents facilitate transmission of bloodborne pathogens such as human immunodeficiency virus [HIV], hepatitis $\mathrm{C}$ virus [HCV] and hepatitis $\mathrm{B}$ virus [HBV] [75]. Estimates based on data from the Centers for Disease Control and Prevention, suggest that a healthcare provider's risk of acquiring HIV infection as a result of percutaneous exposure to an HIV-contaminated device is $0.3 \%$ [76]. According to a study the prevalence of needle stick and sharp instrument injuries in dentists was $19.2 \%$ within the previous six months [75]. Burs represented the most common device as the cause of exposure in this study. Reports of another study carried out in Washington reveals that $66.7 \%$ of the percutaneous injuries are sustained by dentists [76] and most of the injuries $(70 \%)$ occurred during administration of local anesthesia, recapping a needle and performing surgical procedures. According to a study carried out in UK, glove damage is reported in $2 \%$ of latex gloves and $5 \%$ of nitrile gloves which sustained punctures following routine clinical dental procedures [77]. As already cited, the most common "sharps" injuries among dentists continue to rise from needles and drilling instruments, such as burs. Of concern in needle stick injuries, is the fact that they often occur while giving injections, when there is usually some residual bodily fluid in the needle from the punctured site. National and international guidelines, such as the Needlestick Safety Act in 2001 were developed to help minimize the risk of bloodborne pathogen exposure to health care workers including dental settings [78,79]. The infection risk after accidents involving contaminated blood contact depends on various factors, such as: type of exposure, inoculums size, host response, infectious material involved, and the amount of blood [80]. In principle, any accident should be treated equally, regardless of the characteristics of the patient or the accident site. A careful evaluation is necessary to determine the need for post-exposure chemoprophylaxis. Moreover, an analysis of the circumstances of the accidents can contribute to preventing other accidents.

\section{Dental Materials}

There are many potentially toxic materials that are used in dentistry that may pose a health hazard in the absence of appropriate precautionary measures. Most of the dental materials undergo an extensive range of tests both before and after use. Even so, some dental materials are aerosolized during high speed cutting and finishing and may thereby be inhaled by dental staff. Other dental materials are volatile and may give rise to dermatological and respiratory effects [81].

The dangers of chronic exposure to mercury are well documented [81]. On the contrary, it is now recognized that the health hazards of amalgam restorations is negligible with the exception of rare allergic reactions. The greatest exposure to mercury from dentists comes from handling amalgam and amalgam capsules for restorations and storage and disposal of amalgam also represent important sources of exposure [82]. New filling materials have been developed to help reduce the dependence on mercury based substances, such as composite resins, although these may be less durable and clinically effective than mercury amalgam.

Chemicals used in radiology can also lead to occasional health problems. Developing solutions are chemicals used in the reduction of silver bromide ions. These also contain chemicals that control the processing speed, a preservative and a hardening agent. Fixing solutions include a neutralizer, a clearing agent to remove underdeveloped silver bromide ions, a preservative and a hardening agent [83]. There are a number of constituents that may cause health effects: acetic acid, diethyl glycol, glutaraldehyde, hydroquinone, potassium hydroxide etc. In medical imaging, glutaraldehyde is primarily used as a hardening agent to prevent films from sticking together. Skin sensitization and allergic contact dermatitis after occasional exposure have been documented in case of glutaraldehyde. Mixing of processor chemical components also causes the release of sulphur-dio-oxide from decomposition of sulphite. Chronic exposure may result in bronchospasm. Ammonia, a highly soluble respiratory irritant, is another potential by-product released from the breakdown of processing chemicals. Another source of vapor release is the silver recovery unit. It is important that the lid be tightly secured and only opened in a well-ventilated area [83].

\section{Hazard Due to Nitrous Oxide Gas}

The National Institute for Occupational Safety and Health (NIOSH) in 1994 issued a warning to hundreds of thousands of medical, dental and veterinary professionals who work with nitrous oxide $\left(\mathrm{N}_{2} \mathrm{O}\right)$. The Institute warns that even with preventive measures such as scavenging systems in place these workers may be at risk for serious health effects due to their exposure [84].

$\mathrm{N}_{2} \mathrm{O}$ commonly called as laughing gas, is an anesthetic agent used in operating rooms. Workers are exposed to $\mathrm{N}_{2} \mathrm{O}$ while administering the anesthetic gas to patients. To protect workers from the health risks associated with $\mathrm{N}_{2} \mathrm{O}$, operating rooms are often equipped with scavenging systems that vent unused and exhaled gas away from the work area. Recent research shows that these systems can significantly reduce the risk of impaired fertility among female dental assistants exposed to $\mathrm{N}_{2} \mathrm{O}$ [85]. Several human studies have shown that occupational exposure to $\mathrm{N}_{2} \mathrm{O}$, may cause reduced fertility, spontaneous abortions, and neurologic, renal, and liver disease as well as documented decreases in mental performance, audiovisual ability, and mental dexterity in susceptible individuals $[84,85]$.

\section{Legal Hazards}

In every country there are relevant statutes and regulations which apply to the practice of dentistry. The contravention of any of these may warrant that legal actions be brought against a dental practitioner particularly in devel- 
oped countries where the citizens appear more aware of their rights. To help assure a safe work environment in dental treatment, the hazard awareness and prevention of legal risks should be made known to all clinical workers of the dental hospital [1].

\section{Overhead Expenses of a Dentist}

The business demands of a running dental practice can conflict with the need to provide for the dental treatment of all people. Dental fees simply are too high for some. A solo dental practitioner has certain overhead costs to meet: utilities, rent, equipment, supplies, staff, payroll and insurance [86]. These expenses must be met regardless of whether or not patients come and whether or not fees are collected. In addition, the dentist is a highly trained and qualified professional and entitled to a good income. Many dentists graduate from the dental schools heavily in debt because of the high costs of their education and thus have a strong incentive to begin showing profits soon after they begin practice. Failure to meet the overhead expenses and unable to pay the above mentioned debts, creates a tension situation in the minds of the dentist. Many cases of suicidal tendencies are noted because of the above mentioned reasons [86]. Failure to earn more also creates a stress situation in the families of the concerned dentists. Therefore, proper and sound earning is also very essential for a good living and good relationship.

\section{CONCLUSION}

It is very clear from the above discussion that despite numerous advancements, many occupational health hazards are still prevailing in current dental profession. Occupational health hazards are unavoidable in many professions. In order to be a productive professional one must be healthy. High production demands in combination with stressful working conditions will affect health. One thing should kept in mind that every technology, no matter how beneficial, can exert a negative impact on some members of the population. The reality of public health will always involve balancing maximum benefit and minimum harm to the public health and well-being. Immunization against various infectious diseases like HIV, HBV etc. is very essential for every Dental Health Care Worker. Regarding ergonomics, it is very essential to maintain an adequate work posture and that the instruments and furniture that the dentist is working with, have adequate working characteristics to prevent MSDs from developing. Dentists should control their working hours, pace of work, be aware of occupational hazards and observe their mental health. Strategies for improving mental health and reducing the effects of occupational hazards should be developed and implemented in order to secure the well being of dentists. Serious infectious due to percutaneous exposure incidents (PEI) can be avoided by use of appropriate barrier techniques and high level sterilization. Dental personnel should be familiar with the major signs and symptoms of allergic reactions, including anaphylaxis in the case that an allergic emergency should arise during a consultation. Various continuing dental education programs should be organized so that dental professionals can gain knowledge about various newer methods and developments.

\section{CONFLICT OF INTEREST}

None declared.

\section{ACKNOWLEDGEMENTS}

None declared.

\section{REFERENCES}

[1] Adebola FA, Owotade FJ. Occupational hazards among clinical dental staff. J Contemp Dent Pract 2004; 5: 134-52.

[2] Hagberg M, Wegman DH. Prevalence rates and odds ratios of shoulder-neck diseases in different occupational groups. $\mathrm{Br} \mathbf{J}$ Ind Med 1987; 44: 602-10.

[3] Babar-Craig H, Banfield G, Knight J. Prevalence of back and neck pain amongst ENT consultants: national survey. J Laryngol Otol 2003; 117: 979-82.

[4] Scully C, Cawson RA, Griffiths M (1990) Ch 1. Mortality and some aspects of morbidity. In: Occupational Hazards to Dental Staff, London 1990; pp. 1-21.

[5] Brooks SL, Rowe NH, Drach JC, Shipman C Jr, Young SK. Prevalence of herpes simplex virus disease in a professional population. $\mathrm{J}$ Am Dent Assoc 1981, 102: 31-4.

[6] Al-Khatib IA, Ishtayeh M, Barghouty H, Akkawi B. Dentists' perceptions of occupational hazards and preventive measuresin East Jerusalem. East Mediterr Health J 2006; 12: 153-60.

[7] Myers HL, Myers LB. 'It's difficult being a dentist': stress and health in the general dental practitioner. Br Dent J 2004; 197: 8993.

[8] Kaney S. Sources of stress for orthodontic practitioners. Br J Orthod 1999; 26: 75-6.

[9] Shugars DA, DiMatteo MR, Hays RD, Cretin S, Johnson JD. Professional satisfaction among California general dentists. J Dent Educ 1990; 54: 661-9.

[10] Logan HL, Muller PJ, Berst MR, Yeaney DW. Contributors to dentists' job satisfaction and quality of life. J Am Coll Dent 1997; 64: 39-43.

[11] Jolanta Scymanska. Occupational hazards of dentistry. Ann Agric Environ Med 1999, 6, 13-9.

[12] Leggat PA, Kedjarune U. Occupational risks of modern dentistry: a review. J Occup Health 2001; 17: 279-86.

[13] Jacobsen N, Aasenden R, Hensten-Pettersen A. Occupational health complaints and adverse patient reactions as perceived by patients in public health dentistry. Commun Dent Oral Epidemiol 1991; 19: 155-9.

[14] Chopra SS, Pandey SS. Occupational Hazards among Dental Surgeons. MJAFI 2007, Vol.63, Pg 3-25.

[15] Mc Donald RI, Walsh LJ, Savage NW. Analysis of workplace injuries in a dental school environment. Aust Dent J 1997; 42: 10913.

[16] Caballero AJ, Palencia IP, Cardenas SD. Ergonomic factors that cause the presence of pain muscle in students of dentistry. Med Oral Patol Oral Cir Bucal 2010; 15 : e906-11.

[17] Al Wazzan KA, Al Qahtani MQ, Al Shethri SE, Al Muhaimeed HS, Khan N. Hearing problems among dental personnel. J Pak Dent Assoc 2005; 14: 210-4.

[18] Puriene A, Aleksejuniene J, Petrauskiene J, Balciuniene I, Janulyte V. Self-reported occupational health issues among lithuanian dentists. J Ind Health 2008; 46: 369-74.

[19] Pargali N, Jowkar N. Prevalence of musculoskeletal pain among dentists in Shiraz, Southern Iran. International J Occup Environ Med 2010; 1: 69-74.

[20] Puriene A, Aleksejuniene J, Petrauskiene J, Balciuniene I, Janulyte V. Occupational hazards of dental profession to psychological wellbeing. Stomatol Baltic Dental Maxillo J 2007; 9: 72-8.

[21] Davis MS. Variations in patients' compliance with doctors' orders: analysis of congruence between survey responses and results of empirical investigations. J Med Educ 1966; 41: 1037-48.

[22] Hulka BS, Cassel JC, Kupper LL, Burdette JA. Communication, compliance, and concordance between physicians and patients with prescribed medications. Am J Public Health 1976; 66: 847-53.

[23] Corah NL, O'Shea RM, Bissell GD. The dentist - patient relationship: perceptions by patients of dentist behavior in relation to satisfaction and anxiety. J Am Dent Assoc 1985; 111 : 443-6. 
[24] Corah NL, O'Shea RM, Bissell GD. The dentist - patient relationship: mutual perceptions and behaviours. J Am Dent Assoc 1986; 113: 253-5.

[25] Gale EN, Carlsson SG, Eriksson A, Jontell M. Effects of dentist's behavior on patient's attitudes. J Am Dent Assoc 1984; 109: 444-6.

[26] O'Shea R, Corah N, Ayer W: Sources of dentists' stress. J Am Dent Assoc 1984; 109: 48-51.

[27] Simon JF, Peltier B, Chambers D, Dower J. Dentists troubled by the administration of anesthetic injections: long-term stresses and effects. Quintessence Int 1994; 25: 641-6.

[28] Gortzak RA, Stegeman A, Ten Brinke R, Peters G, Abraham Inpijn L. Ambulant 24-hour blood pressure and rate of dentists. Am J Dent 1995; 8: 242-4.

[29] Rankin JA, Harris MB. Stress and health problems in dentists. J Dent Pract Adm 1990; 7: 2-8.

[30] Wall TP, Ayer WA. Work loss among practicing dentists. J Am Dent Assoc 1984; 108: 81-3.

[31] Deverall A. The health of dentists in South Africa. J Dent Assoc South Africa 1969; 24: 368-71.

[32] Leggat PA, Chowanadisai S, Kukiattrakoon B, Yapong B, Kedjarune U. Health of dentists in Thailand. Intern Dent J 2001; 51: 34852.

[33] Smith DR. Leggat PA. A comparison of tobacco smoking among dentists in 15 countries. Intern Dent J 2006; 56: 383-8.

[34] Leggat PA, Kedjarune U, Smith DR. Occupational health problems in modern dentistry: a review. J Indus Health 2007; 45: 611-1.

[35] Sinclair NA, Thomson WM. Prevalence of self-reported hand dermatoses in New Zealand dentists. New Zealand Dent J 2004; 100 : 38-41

[36] Burke FJ, Wilson NH, Cheung SW. Factors associated with skin irritation of the hands experienced by general dental practitioners. Contact Dermatitis 1995; 32: 35-8.

[37] Jacobsen N, Hensten-Pettersen A. Occupational health problems among dental hygienists. Commun Dent Oral Epidemiol 1995; 23: 177-81.

[38] Hamann CP. Natural rubber latex hypersensitivity: incidence and prevalence of type 1 allergy in dental profession. J Am Dent Assoc 1998; 129: 43-54.

[39] Dalgleish AG, Malkovsky M. Surgical gloves as a mechanical barrier against human immunodeficiency virus. Br J Surg 1988; 75 : 171-2.

[40] Charpin D, Vervolet D. Epidemiology of immediate-type allergic reactions to latex. Clin Rev Allergy 1993; 11: 385-90.

[41] Fisher AA. Contact urticaria and anaphylactoid reaction due to cornstarch surgical glove powder. Contact Dermatitis 1987; 16: 244-5.

[42] Turjanamaa K, Alenius H, Mäkinen-Kiljunen S, Reunala T, Palosuo T. Natural rubber latex allergy. Allergy 1996; 51: 593-602.

[43] Tarlo SM, Sussman G, Contala A, Swanson MC. Control of airborne latex by use of powder-free gloves. J Allergy Clin Immunol 1994; 93: 985-9.

[44] Goran Tosic. Occupational hazards in dentistry-part one: allergic reactions to dental restorative materials and latex sensitivity. Facta Universitatis 2004; 2 : 317-24

[45] Rustemayer T, De Groot J, Von Blomberg B.M. Cross-reactivity patterns of contact-sensitizing methacrylates. Toxikol Appl Pharmacol 1998; 148: 83-90.

[46] Kanerva L, Estalender T, Jolanki R, Alanko K. False-negative patch test reactions due to a lower concentration of a patch test substances then declared. Contact Dermatitis 2000; 42: 289-91.

[47] Lonnroth E C, Shahnavaz H. Use of polymer materials in dental clinics. Swed Dent J 1997; 21: 149-50.

[48] Piirila P, Kanerva L, Keskinen H. Occupational respiratory hypersensitivity caused by preparations in dental personnel. Clin Exp Allergy 1998; 28: 1404-11.

[49] Nayebzadeh A, Dufresne A. Evaluation of exposure to methyl methacrylate among dental laboratoty technicians. Am Ind Hyg Assoc J 1999; 60: 625-8.

[50] Bahannan S, el-Hamid AA, Bahnassy A. Noise level of dental handpieces and laboratory engines. J Prosthet Dent 1993; 70: 35660.

[51] Setcos JC, Mahyuddin J. Noise levels encountered in dental clinical and laboratory practice. Int J Prosthodont 1998; 11: 150-7.

[52] Sampio Fernandes JCS, Carvalho APO, Gallas M, Vaz P, Matos PA. Noise levels in dental schools, Eur J Dent Educ 2006; 10: 32-7.
[53] Trenter SC, Walmsley AD. Ultrasonic dental scaler: associated hazards. J Clin Periodontol 2003; 30: 95-101.

[54] Kai M, Luebeck EG, Moolgavkar SH. Analysis of the incidence of solid cancer among atomic bomb survivors using a two-stage model of carcinogenesis. Radiat Res 1997; 148: 348-58.

[55] Wang JX, Inskip PD, Boice JD, Jr., Li BX, Zhang JY, Fraumeni JF Jr. Cancer incidence among medical diagnostic X-ray workers in China, 1950 to 1985 . Int J Cancer 1990; 45: 889-95.

[56] Yenogopal V, Naidoo S, Chikte UM. Infection control among dentists in private practice in Durban. SADJ 2001; 56: 580-4.

[57] Zielinski JM, Garner MJ, Krewski D, et al. Decreases in occupational exposure to ionizing radiation among canadian dental workers. J Can Dent Assoc 2005; 71: 29-33.

[58] Leggat PA, Chowanadisai S, Kukiattrakoon B, Yapong B, Kedjarune U. Occupational hygiene practices of dentists in southern Thailand. Int Dent J 2001; 51: 11-6.

[59] Mandel ID. Occupational risks in dentistry: comforts and concerns. J Am Dent Assoc 1993; 124: 40-9.

[60] Kuroyanagi K, Hayakawa Y, Fujimori H, Sugiyama T. Distribution of scattered radiation during intraoral radiography with the patient in supine position. Oral Surg Oral Med Oral Pathol Oral Radiol Endod 1998; 85:736-41.

[61] Caballero AD, Palencia IP, Cardenas SD. Ergonomic factors that cause the presence of pain muscle in students of dentistry. Med Oral Patol Oral Cir Bucal 2010; 15 : e906-11.

[62] Marshall ED, Duncombe LL, Robinson RQ, Kilbreath SL. Musculoskeletal symptoms in New South Wales dentists. Aust Dent J 1997; 42: 240-6.

[63] Bassett S. Back problems among dentists. J Can Dent Assoc 1983; 49: 251-6.

[64] Biller FE. Occupational hazards in dental practice. Oral Hyg 1946; $36 ; 1194$

[65] Moen BE, Bjorvatn K. Musculoskeletal symptoms among dentists in a dental school. Occup Med 1996; 46: 65-6.

[66] Rundcrantz BL, Johnsson B, Moritz U. Cervical pain and discomfort among in dentist. Epidemiological, clinical and therapeutic aspects. Part 1. A survey of pain and discomfort. Swed Dent J 1990; 14: 71-80.

[67] Rundcrantz BL, Johnsson B, Moritz U. Pain and discomfort in the musculoskeletal system among dentists: a prospective study. Swed Dent J 1991; 15: 219-28.

[68] Rundcrantz BL, Johnsson B, Moritz U, Roxendal G. Cervicobrachial disorders in dentists: a comparison between two kinds of physiotherapeutic interventions. Scand J Rehabil Med 1991; 23: 11-7.

[69] Milerad E, Ekenvall L. Symptoms of the neck and upper extremities in dentists. Scand J Work Environ Health 1990; 16: 129-34.

[70] Dawson OM, Hallett M, Millender LH. Digital nerve entrapment in the hand. In: Entrapment neuropathies. Boston /Toronto: Little, Brown and Company 1983: pp. 185-94.

[71] Ostrem CT. Carpal tunnel syndrome. A look at causes, symptoms, remedies. Dent Teamwork 1996; 9:11-15.

[72] Ramos-Gomez F, Ellison J, Greenspan D, Bird W, Lowe S, Gerberding JL. Accidental exposures to blood and body fluids among health care workers in dental teaching clinics: a prospective study. J Am Dent Assoc 1997;128: 253-61

[73] Bellissimo-Rodrigues WT, Bellissimo-Rodrigues F, Machado AA. Occupational exposure to biological fluids among a cohort of Brazilian dentists. Int Dent J 2006; 56: 332-7.

[74] McCarthy GM, Koval JJ, MacDonald JK. Occupational injuries and exposures among Canadian dentists: the results of a national survey. Infect Control Hosp Epidemiol 1999; 20:331-6.

[75] Martins A M, Santos NC, Lima MD, Pereira RD, Ferreira RC. Needlestick and sharp instrument injuries among dentists in Montes Claros, Brazil. Arquivos Odontol 2010; 46; 127-35.

[76] Shah SM, Merchant AT, Dosman JA. Percutaneous injuries among dental professionals in Washington State. BMC Public Health 2006; 6: 269.

[77] Murray CA, Burje FJ, McHugh S. An assessment of the incidence of punctures in latex and non-latex dental examination gloves in routine clinical dental practice. Br Dent J 2001; 190: 377-80.

[78] Occupational Safety and Health Administration. Final standard for occupational exposure to blood borne pathogens: December 6 , 1991. 29 CFR 1910.1030. 
[79] The WHO Strategy regarding injection safety [monograph on the internet]; 2010 [cited 2010 March 15]. Available from: http://www.who.int/injection_safety/about/strategy/en

[80] Haiduven DJ, Simpkins SM, Phillips ES, Stevens DA. A survey of percutaneous /mucocutaneous injury reporting in a public teaching hospital. J Hosp Infect 1999; 41:151-4.

[81] Pohl L, Bergman M. The dentist's exposure to elemental mercury vapor during clinical work with amalgam. Acta Odontol Scand $1995 ; 53 ; 44-8$

[82] Martin MD, Naleway C, Chou H-N. Factors contributing to mercury exposure in dentists. J Am Dent Assoc 1995; 126; 1502-11.
[83] Anderson PC, Alice E. Pendleton AE. The Dental Assistant. $7^{\text {th }}$ ed. Delmar Thomsom Learning 2001

[84] Nitrous Oxide Continues to Threaten Health Care Workers [monograh on the internet]; 2008 [cited 2008 March 11]. Available from: www. cdc.gov/niosh/updates/94-118.html

[85] Samaranayake LP, Anil S, Scully C. Occupational Hazards in Dentistry: Part 1. FDI 2001; 8-12

[86] Burt BA, Eklund SA. Dentistry, Dental Practice and the Community. $6^{\text {th }}$ ed. Missouri: Elsevier Saunders 2005.

Received: August 29, 2011

Revised: September 19, 2011

Accepted: September 22, 2011

(C) Gambhir et al.; Licensee Bentham Open.

This is an open access article licensed under the terms of the Creative Commons Attribution Non-Commercial License (http://creativecommons.org/licenses/by-nc/3.0/) which permits unrestricted, non-commercial use, distribution and reproduction in any medium, provided the work is properly cited. 